Portland State University

PDXScholar

Engineering and Technology Management

Faculty Publications and Presentations

2019

\title{
A Preliminary Strategic Framework for Enhancing the Sustainability of International Technology Transfer: The Case of Libya
}

Rafaa Ibrahim Khalifa

Portland State University, rafaa.khalifa@gmail.com

Maoloud Dabab

Portland State University

Husam Barham

Portland State University

Follow this and additional works at: https://pdxscholar.library.pdx.edu/etm_fac

Part of the Mining Engineering Commons, and the Operations Research, Systems Engineering and Industrial Engineering Commons

Let us know how access to this document benefits you.

\section{Citation Details}

R. Khalifa, M. Dabab and H. Barham, "A Preliminary Strategic Framework for Enhancing the Sustainability of International Technology Transfer: The Case of Libya," 2019 Portland International Conference on Management of Engineering and Technology (PICMET), Portland, OR, USA, 2019, pp. 1-9.

This Article is brought to you for free and open access. It has been accepted for inclusion in Engineering and Technology Management Faculty Publications and Presentations by an authorized administrator of PDXScholar. Please contact us if we can make this document more accessible: pdxscholar@pdx.edu. 


\title{
A Preliminary Strategic Framework for Enhancing the Sustainability of International Technology Transfer: The Case of Libya
}

\author{
Rafaa Khalifa, Maoloud Dabab, Husam Barham \\ Dept. of Engineering and Technology Management, Portland State University, Portland, OR - USA
}

\begin{abstract}
International Technology Transfer (ITT) has played a crucial role not only in the industrial growth of developing countries but also in enhancing the competitiveness of their enterprises in the global market. Libya is a North African country that is currently shifting from a strictly petroleum/mineral based economy to a broad-based economy competing with distinct advantages through selecting, planning, and adopting the right technology for the domestic market. This significant transition requires strategic access to global technology transfer. In this paper, a preliminary strategic framework is designed to enhance the sustainability of the ITT process from international donators to the Country of Libya. The research provides a systematic technology transfer process between the donor and recipient, which focuses on ITT challenges in term of barriers and planning. Two principle research questions are proposed to cover these challenges and help to develop a unique strategic framework: What are the most significant barriers for an international technology transfer between developed and developing countries? Moreover, how should the Country of Libya plan strategically to overcome those barriers and achieve sustainable technology receiving and adoption? In this paper, an in-depth literature investigation is used to answer both questions, leading to the development of a sustainable strategic framework that can help improve the ITT process from international donators to the Country of Libya. Additionally, the research highlights recommendations that can help to improve the quality of the technology transfer process itself in an international context.
\end{abstract}

\section{INTRODUCTION}

International technology transfer (ITT) is a broad set of processes that focus on what needs to be done to transfer technology across international borders. The transferor and transferee can be government, nongovernmental organizations (NGO's), private sectors, or research institutions [1]. The ITT could happen in different ways; it can be between government labs to private sectors firms or between private sector firms of different countries [1]. Also, the transfer could happen through academic, government and industry collaborations [2]. There are two types of ITT, vertical and horizontal. Vertical technology transfer refers to the transfer of technology from basic research to development and production respectively. While the horizontal technology transfer refers to the movement and application of technology from one place or context to another [3]. There are several reasons why some countries or companies need to transfer its technology to other parties; such as the lack of manufacturing capacity or lack of resources to launch product commercially. Moreover, the lack of marketing distribution and distribution capability are among the most important reasons for transferring technology to others [4].

The transferor and transferee should be fully aware of their capabilities and requirements before launching technology transfer. Technological evaluation, requirements, capacities recognition, and selection of technology methods are very important issues to be considered as part of the ITT process [1]. Figure 1 shows a basic TT network and the relationship between each player in the technology transfer process [4]. A successful transfer can only occur if the recipient is sufficiently capable of maintaining the introduced production system. Without this capability, it is difficult to improve or revise technology [4]. Clear information including the agreed cost can help to smooth the transfer of the technology between the transferee and transferor [5]. The technology transfer will most likely be successful if the transferring process was wellunderstood and its performance predicted accurately [1]. A successful technology transfer generally needs facilitators, funders, or both [6]. Challenges that might affect the success of technology transfer varies considerably. In order to get the sustainability of the technology transfer, the technology needs to be adapted to the context at the recipient site [7].

Technology transferred from developed countries can help developing countries to bridge the technology gap and alleviate their economic difficulties [8]. Moreover, several criteria are considered in assessing the results of technology transfers. Research indicates that cost, sustainability, and contribution of the technology transfer, have considerable influence to improve enterprises and the country's economy [9]. However, technology transfer costs, infrastructure, and policies are considered as significant challenges facing developing countries [10]. Libya is one of the developing countries that have the potential to become an international hub between Africa and Europe. ITT in Libya has not been explored to a great extent yet [11]. Currently, the use of technology in Libya is not reaching its maximum potentials due to the lack of a strategic approach that helps to transfer and adopt the right technology.

Therefore, the main objectives of this research are to explore the previous literature and lessons learned that described the ITT challenges, models, and process in the world. Then, leverage the findings to suggest a preliminary strategic framework that Libya can use as guidance to enhance 


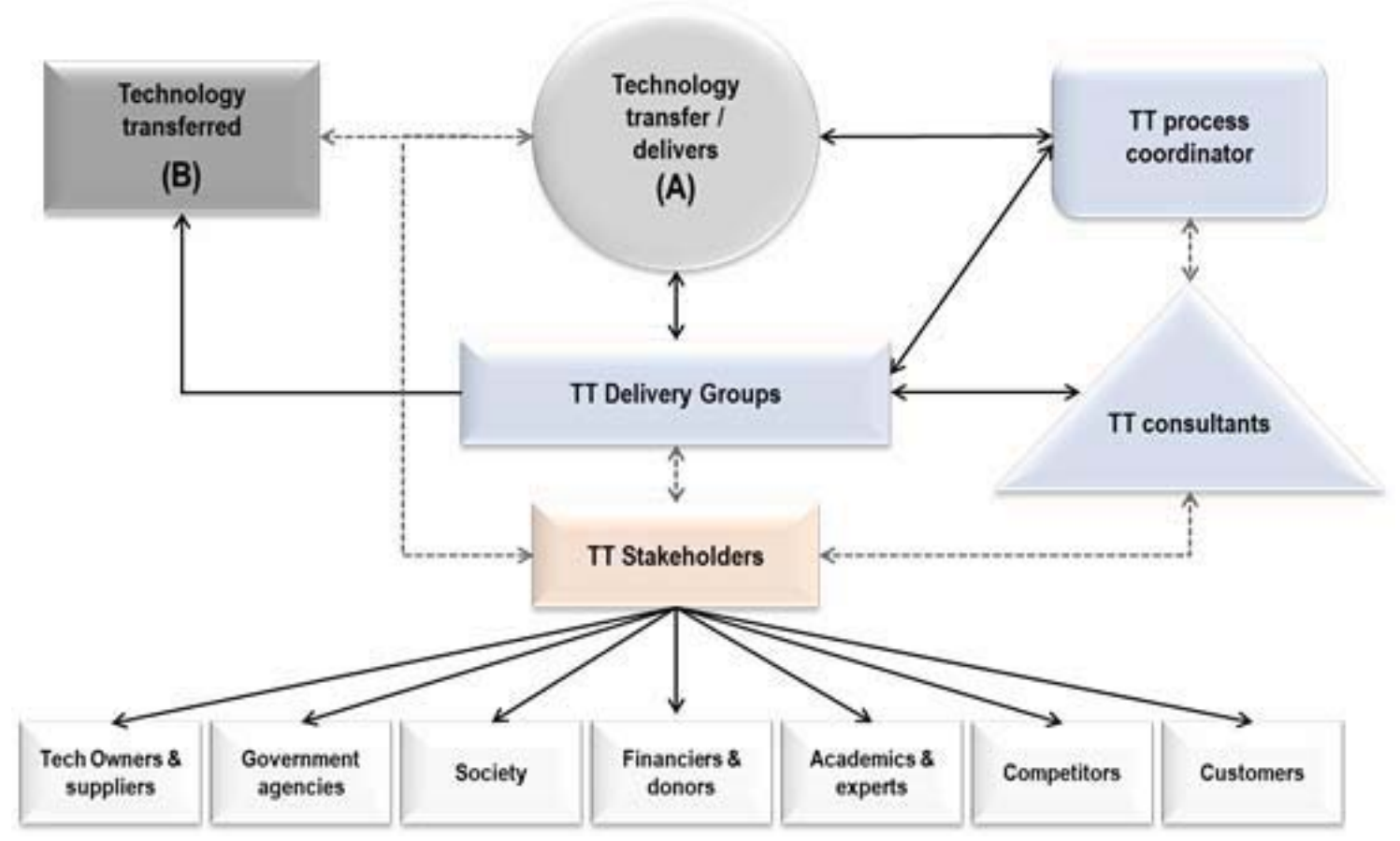

Fig. 1. Basic Technology Transfer Network, adapted from [61]

the sustainability of the ITT process from international donator to Libya domestic market.

\section{LITERATURE REVIEW}

Following is a review of literature about technology transfer, why it is important, what are the barriers facing technology transfer, and what are the main models available regarding international technology transfer.

\section{A. Technology Transfer Definitions}

Research defines the term "Technology Transfer" from different viewpoints. TT can be defined as the process of movement of technology from one entity to another [12]. The movement may involve physical assets, technical knowledge, or know-how [13]. Technology transfer refers to concerted projects that allow the recipient to access or adopt comprehensive technological capabilities of the transferor. TT is considered as an area of interest for several disciplines, including economy, business, and technology, among others [14]. The main focus of TT is to improve the competitive advantage of firms through the enhancement of customer value from both business and technology perspectives [15]. Furthermore, ITT is the diffusion of technology from the original location of its creation to other markets globally. This diffusion may take place through market transactions, with transferor who sells a product, process or knowledge to another [16].

Moreover, ITT can be separated within the full range of international technology flow in three main categories.
The first category is related to manufacturing technique and know-how accompanied by technical assistance and marked by the user firm. The ssecond category is related to the flow of products presenting technology, which can help in producing other products. The last category is related to the flow of services involving some degree of technology supporting with consulting engineering [17].

\section{B. Importance and Reasoning for International Technology Transfer}

International technology transfer may result in significant growth in the productivity of the existing labors, national resources, and organizations structure by increasing the capabilities of outputs [18]. Also, ITT helps to maintain the value or flow of the input with any change. The main reason for ITT is not just to develop or increase the productivity of the beneficiary only. But also, to catch up and implement the right technology. If the main purpose of ITT is not achieved, the sustainability of the TT might be failed. Technology transfer is not only benefiting the developing countries but also helps developed countries to expand and protect their markets. If technology is successfully transferred, both developing and developed countries will achieve supportive benefits [19]. Technology transfer can be important to enhance the economic development of developing countries by improving their firms' competitiveness globally. Also, technology transfer may increase the availability of managerial knowledge that helps countries to achieve or maintain its market share in the global market. Expanding the living standard of people is also considered as a result of technology transfer in some developing countries. 


\section{Technology Transfer Barriers}

Previous studies have found barriers related to ITT process. In many developing countries, governments build their national technological base by ITT projects [20][21]. To adopt new technology effectively, recipients need to cultivate local technological capability [21]. Three kinds of technological capabilities: production, investment, and innovation were addressed in literature as hard to be achievable in most developing countries [22]. Some significant ITT barriers that simulate the relationship between technological complexity and organizational modes were investigated by literature [23]. For example, in the mid-80s Mytelka had established a statistically significant negative correlation between the complexity of the technology and foreign ownership of Latin American firms [23]. Recently, the achievement of technological progress has become more complex and uncertain, and new technologies need to pass certain tests and procedures [24] [25]. Knowledge and expertise are essentially required for adopting new technologies. For example, the complexity of production technologies, knowledge, and technical know-how have become important barriers in ITT projects. To get ITT benefits, firms and organizations most likely push to delay highly advanced technologies until they obtain sufficient technical know-how at implementation and operations stages to both implement and operate it successfully [26].

Some aspects of technology such as knowledge and skills are intangible [27]. These aspects might be much more critical than the physical aspects of transferring the required technologies successfully. Successful ITT projects showed the importance of awareness and training as part of technology transfer to mitigate ITT barriers. For example, in Japan, during the industrialization era, the country provided high capabilities for learning new technologies. An example is when experts from universities and businesses contributed to facilitating the transfer of the marine steam turbine generator. They developed efficient coal-fired thermal power plants by increasing the temperature of its steam engines [28]. In contrast, in the late 19th century in Indonesia, farmers failed to transfer agricultural machines for farm mechanization because of the lack of education and training, along political, and other compatibility issues [29].

Therefore, Barriers identification and analysis are considered significant tasks during ITT activities. All ITT activities are performed by a joint workgroup from transferor and transferee. The workgroup is guided by certain specifications and requirements. Most of the time, the technology recipient hires a consultant or facilitator who has experience and knowledge of the national requirements to facilitate the TT process. The transferor has less contribution in identifying the TT barriers. Moreover, Wie [30] highlighted the need to close the gap between developed and developing countries in the area of ITT. He also lists four significant issues, knowledge, training, skills, and infrastructure that need to be considered during TT activities.

\section{Technology Transfer Planning}

Since technology transfer is increasingly becoming important for developing countries, technology transfer planning has been playing a significant role to ensure a successful technology transfer. The importance of achieving a greater collaboration between the developed and developing countries has been recognized in the recent past. Also, the strategic planning of ITT has been emphasized in many countries as an essential element for proper technology transfer. ITT planning is a process that describes items and contents of technology including all detailed procedures within pre-agreement between transferor and transferee [1]. Poor planning including internal forces can contribute to the failures of ITT for the technology beneficiaries [4].

Goals and Objectives of TT are required for successful cooperation between the transferor and transferee [31]. The national and global goals of technology needs must be considered in short and long strategic planning [32]. Strategic planning demonstrates not only where an organization is going or what actions are needed, but it also monitors organization performance against strategic goals [33]. The technology strategy should be considered in the long-term vision of developing countries. The integration between business goals and the technology objectives lead to sustainable technology transfer between the transferor and transferee [34]. Chen et al. (2009) refers to the effectiveness of different planning modes and ideas that have been explored and proposed regarding the development of a technology plan. The same authors proposed a connection between two planning modes combined with scenarios. In their proposal, they linked the technology choices to an organization's overall mission through alignment with goals and strategies [35]

\section{E. International Technology Transfer Models}

Reviewing the literature about TT models revealed that during the past three decades, several technology transfer models were introduced by TT project' managers, consultants, and researchers. TT models were proposed as a result of the difficulties and complexities of transferring the technology from firm to firm or from country to country. The main objective of these models was to facilitate effective technology planning and its implementations in different fields. TT models can be qualitative or quantitative. Qualitative models often have objectives and factors that are related to managing TT issues and its success. While quantitative models are aimed at quantifying parameters of significance in technology management and analyzing them in relation to the transferring mission and goals [36]. Previous studies have used quantitative approaches, mostly through survey instruments and Data analysis [37].

Therefore, this paper investigates some qualitative models that might help to achieve the study objective from the planning perspective. In 1971, Samuel Bar-Zakay [38] developed a comprehensive technology transfer model based on the project management approach. The model called "The Bar-Zakey Model" and it divided the TT process into four stages, search, adaption, implementation, and maintenance. The model describes the responsibilities of each transferor and transferee in a parallel pattern. Jagoda [36] argued that the BarZakay model was just useful in the era between the 1960s and 1970s. He emphasized that the owner of the technology was mainly the passive recipient. The beneficiary was entirely 
dependent on aid programs for the purchase of technology. Also, the government was involved in the technology process such as determining the rate, direction, and scope of technology flows.

In 1976, Behrman and Wallender [39] presented another model with seven stages as part of the ITT process which was more relevant to the corporations globally. The model includes the planning, business case, and assessment of resources. It describes the steps of information and the decisions that help to understand the targeted technologies. Adopting the product process, improving the local skills, and providing external support reflect the model strength. However, the model shows a disadvantage within the first three stages; the transferee has less involvement in the technology transfer process.

In 1981, Dahlman and Westphal [40] introduced their model based on their experience in Korea. They presented a nine-stage process model. The model focuses on the importance of training and developing troubleshooting skills. Despite the fact that the model was designed to improve the Behrman and Wallender model's gap in the engineering skills and negotiation, however, the model did not improve this feature practically in many developing countries.

In 1987, Schlie, Radnor, and Wad [41] proposed a simple model including seven elements that can influence the planning, implementation, and sustain the TT projects. The first and second elements describe the relationship between the transferor and transferee in term of the TT process. The third and fourth elements explain the type of technology that is being transferred and the mechanism of transferring. The fifth and sixth elements refer to the transferor and transferee environment. The last element explains the conditions and requirements of the transaction process between the transferor and transferee including exchange rates, investment climates, trade negations, the balance of trade, relative technological levels, and the status of intellectual property protection. This model is useful for the business setting, and the transferee does not have clear responding guidelines for TT project.

In 1990, Chantramonklasri [42] innovated a unique model that improve the Dahlman and Westphal model. The Chantramonklasri model proposed five phases starting with pre-investment and feasibility study phase. Developing an engineering design and specifications are considering as a second phase. The third and fourth phases focus on the installation, testing, and workforce selection. The last phase includes the final production. The model did not solve the gap in Dahlman and Westphal model completely. Other models were developed based on the rapidly industrializing countries, integrating the project management in TT processes and the unexpected barriers of the TT locally or internationally. For example, [43] referred to the importance of managing the TT barriers to achieve an effective technology transfer. They emphasized that the transferor and transferee should look for a win-win situation during the technology transfer process.

In 2005, Jagoda and Ramanathan were the first to describe the TT as part of a planning approach [44]. They divided the TT process into multifunctional activities which called the stages. Following each stage, there is a checkpoint or gate at which critical questions are asked, to validate the stage immediately before moving to the next stage.

Recently, in 2015, Nirmal, Bhar, and Pandurangan present and discuss the history of TT models that are developed during the period from 1960 to 2013 [45]. They emphasize that the limitations of the existing models have proved the need for the development of a comprehensive model which consider the TT purpose and its challenges [45].

\section{ReseARCh Methodology}

In order to develop a strategic framework for sustainable technology transfer in Libya, the authors first conducted extensive literature review to identify the theoretical aspects of research that have been done in the area of International Technology Transfer (ITT), with focus on the key concepts, challenges, models, and lessons learned about ITT from developed countries to developing countries.

Then, the current TT situation in Libya, the focus of the case study, was investigated. The case of Libya represents an example that demonstrates the relationship between the donor and recipient in term of the ITT process. .

Finally, the authors used literature review findings, the analysis of the current situation in Libya, and their knowledge of the region to develop a unique strategic framework of ITT that can be used by Libya to enhance the sustainability of technology transfer in that country.

Moreover, the literature on Libya's level of technology transfer is still rare and generalized. To get the required information regarding TT in Libya, the authors depended on historical literature that was published by or can be found in some Libyan research, service, and industrial organizations. The experience of the authors in the region and the field of technology management was used to identify and validate the valuable data for the proposed framework.

\section{CASE Study}

\section{A. Overview of Technology Level in Libya}

In 2018, the population of Libya had reached 6,470,956 people, lives within an area of 1,777,060 sq. km. [46]. Libya has significant natural resources including oil, gas, and minerals [47]. However, Libya is considered one of the lesssuccessful developing countries. The country has a weak innovation system and lack of new technologies adoption in most sectors comparing with other neighboring countries. Less-successful developing countries have critical systematic problems that require significant efforts to be solved [48]. In the last decade, there were humble to moderate efforts to adopt recent advances in technology in government and semigovernment sectors like oil and gas, telecommunication, and banking [49].

Moreover, the Libyan public sectors' readiness for adopting technology involves many aspects such as the type of organizations and its leadership. In addition, technology adoption influences and is influenced in Libya by social, culture, decision making, strategy, and risk-taking factors. For 
instance, information and communication technology advances in the last decade are becoming more accepted by Libyans. By December 2017, Libya had 3,800,000 users of the internet and other technologies, and they present $58.7 \%$ of the population. In the same year, 3,500,000 people were identified as Facebook users, which is about $54.1 \%$ penetration rate [46]. Recently, the government realizes that it is time to encourage and support all public and private sectors to adopt recent advances in technology. However, there is still a lack of adequate technology infrastructure in the country. So, the government needs to invest in technology infrastructure and innovations [50]. Although Libya suffers from poor technology infrastructure, the country possesses many positive characteristics for implementing the right technology in different sectors [49]. The government is keenly aware that rebuilding and maintain technology infrastructure is necessary for the country to attract foreign investment. The true benefit of foreign technologies acquisition is to adopt the last updated technology. In early of 2012, Libya government started a successional plan for organizations' future leaders. The plan aims to fund Libya's brightest students through the Ministry of Higher Education and Scientific Research to study overseas. The Ministry invests in Libyan students at some international best universities, where students will have the chance to learn about new technologies and its applications. Students then apply what they have learned once they completed their study and returned. Libya Vision 2020 requires a society that is innovative and forward-looking. The vision emphasizes the importance of adopting new technologies that are catalysts for social progress and the basis for a prosperous economy [50].

\section{B. Technology Transfer History}

In the past, the Libyan government was not keen to be involved in adopting new technologies in its organizations due to the lack of educational system and a culture of avoiding anything new and uncertain [49]. Nowadays, some public and private sectors have started to seen organizations adopting new technologies. Academia and research centers have introduced some initiatives and programs to help Libyan public and private sectors to build up technology knowledge. This is a positive sign of realizing the importance of adopting new technologies in the country, which is furthered advanced by cooperating with international technology donors. While Libya has made significant improvements in educational access and equity [50], the country is still facing a poor quality infrastructure and a lack of strategic approach or model that help to gain the right technologies. In 2007 Libya allocated \$13.4B for technological development in many sectors; this amount was representing $60 \%$ of the total annual budget [51]. The decision was taken with a lack of a strategic framework or plan for the IT process and its implementation which resulted in poor results.

Finally, culture and skills are among the critical issues that might face technology transfer and adoption in Libya. The issue of culture in the ITT process has been discussed by [52] and presented its impact on the recipient. The issue of culture should be identified in the case of ITT activities. Otherwise, the transferring process might fail [53]. Furthermore, local skilled workers are critical to developing any country, and without them, governments and their local firms would be depending on international resources, which is not sustainable [54].

Mohamed et al. highlighted these issues in their study of the importance of key factors and sub-factors affecting the ITT process in Libya [53]. They discussed the importance and the relationship between those factors to determine government role, culture and transfer mode in the overall ITT management in the Libyan oil and gas industry. The lack of infrastructure, national crisis, and unstable power have had a devastating effect on technology sustainability in Libya [55]. Therefore, inadequate information, missing feedback, lack of awareness and training needs to be addressed in any proposed framework for sustaining the technology transfer in Libya.

\section{ITT Models Development Specific of the ICT and Petroleum Industry in Libya}

The use of recent advances in high tech in Libya is minimal [55]. However, in the last decade, ICT and petroleum industries have played a remarkable effort in transferring and adopting new technologies as a way for sustainable development. Following is a review of previous ITT research specific to Libya.

Hassan et al. (2016) developed an ITT model for the ICT industry in Libya. The model aims to describe the TT process to transfer advanced international ICT technology to companies and ICT-based SME projects in Libya [56]. Figure. 2 demonstrates the model elements that influence the effectiveness of the ITT process and its outcomes. Five elements are adapted from the literature review and interrelated to present a successful implementation of the TT process. However, the proposed model demonstrates a general framework, and the study findings were depended on literature and provided trends and opinions which are drawn from one case study. The model presents a systematic ITT process but did not provide enough focus on the sustainability of ITT.

Another ITT study related to Libya was done by Mohamed et al. (2012). This study presented a conceptual model for the ITT process in Libya. The model was developed to enhance the ITT for the petroleum industry in the fields of management, planning, engineering, operating and manufacturing. Adopting technologies can be seen clearly in the petroleum sector due to the requirements of high-tech in exploration, drilling, and production of oil and gas. [53]. The study investigated key elements that were arranged into a conceptual model to show its theoretical relationships and to demonstrate the ITT process. As illustrated in Figure. 3, the model shows the interface between TT support, TT infrastructure, TT environment, and the receiving company's learning capability to achieve TT performance as an outcome. However, this conceptual model is more focused on the petroleum sector. Other sectors like the public sector do not fit properly in this model, as they depend on other local resources and national plans. Also, the model is focused on the transferee and authors have neglected the transferor roles in the TT process as the model was designed for the petroleum sector which operates on the basis of partnership with foreign international companies [49] 


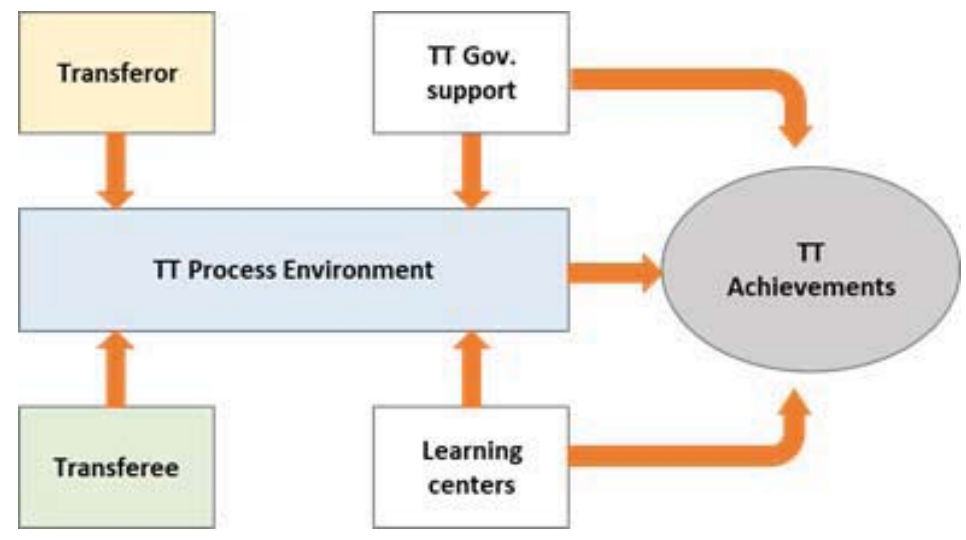

Fig. 2. ITT Model for ICT Industry in Libya, adapted from [53]

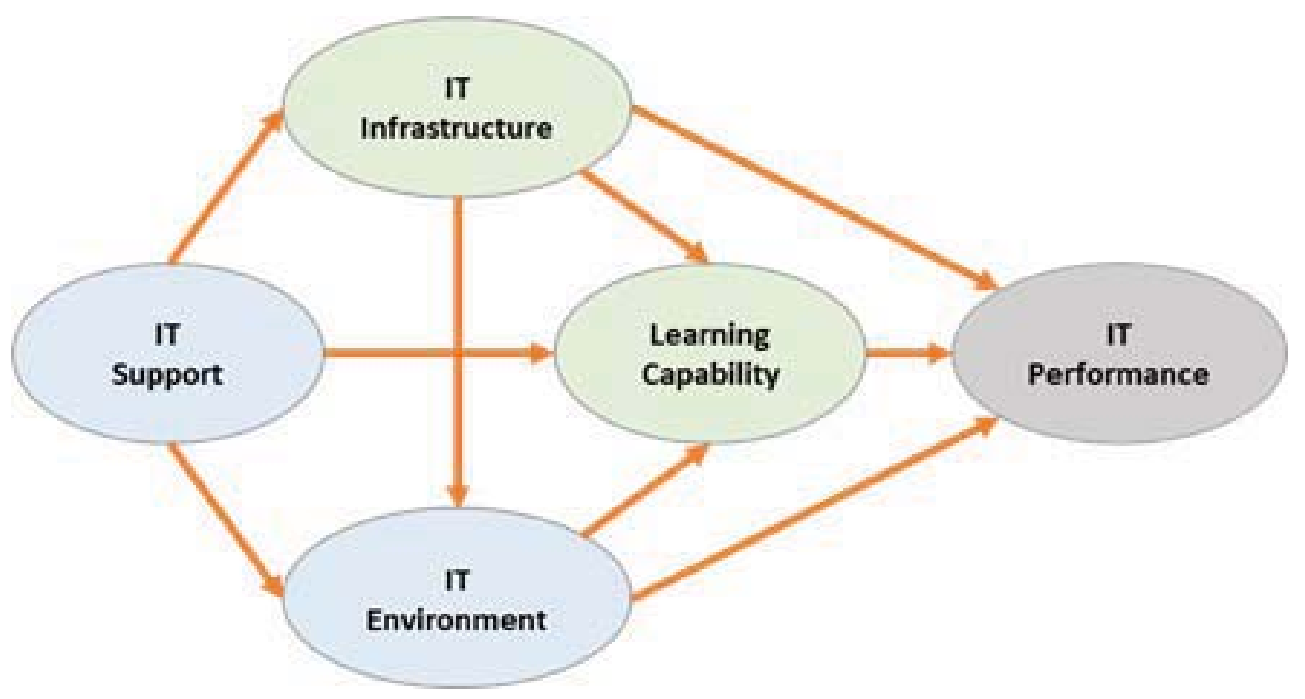

Fig. 3. Conceptual model for IT in the Libyan petroleum industry, adapted from [53]

However, this conceptual model is more focused on the petroleum sector. Other sectors like the public sector do not fit properly in this model, as they depend on other local resources and national plans. Also, the model is focused on the transferee and authors have neglected the transferor roles in the TT process as the model was designed for the petroleum sector which operates on the basis of partnership with foreign international companies [49].

\section{DISCUSSION}

\section{A. Strategic Framework Development}

It is believed that one of the significant factors for a successful technology transfer is the development of a framework that helps to enhance the sustainability of the ITT process [57]. Therefore, the goal of this research is to propose a preliminary strategic framework that can promote ITT sustainability for the country of Libya by considering the ITT process as multi actions and activities. To develop the model, the authors leveraged on an extensive literature review of ITT in general and about the current situation in Libya (please refer to the literature review and case study sections).

Cooper (2001) introduces a unique stage-gate model which aims to develop the product development process depending on the strategic planning and project management knowledge [58]. Jagoda and Ramanathan (2005) describe the model activities which are called the stages [44]. The model is designed to provide managers with the ability to study the process of activities, milestones, and decision-point sequences. The model was adopted for developing a systematic approach for ITT planning and managing its process [59]. The model breaks the ITT process down into stages based on project activities and gates to describe business evaluations and decision-making. It classifies the stages and gates into three groups: Initiation, Planning, and Execution and Evaluation. The model incorporates three main activities: pre-development, 
development, and commercialization into one complete sustainable and robust process. These activities are designed to gather information and reduce uncertainty and risk during the transferring process. The model gates mainly serve as qualitycontrol checkpoints [57]. In general, the model process is designed to help to move the ITT project from one stage to the next stage through certain communications, monitors, and decision points [60].

\section{B. The Proposed Strategic Framework}

In this study, the proposed framework focuses on the same basic structure of a stage-gate approach from ITT planning, evaluating, and managing perspectives. The framework is considered as a qualitative model which is designed based on the previous efforts in ITT combining both theoretical literature and practical lessons learned. Also, the framework is influenced by previous ITT processes that were introduced by research for the Libyan ICT and petroleum sectors [53][56]. In this framework, as shown in Figure 4, the ITT process is divided into multifunctional activities and is distributed between two main phases. Ten stages demonstrate the responsibility of both transferor and transferee through the implementation of phase 1 and 2, respectively.

In each phase, five of the principal activities and actions, that are identified in this research as key ITT stages, are required to ensure the sustainability of ITT for the case of Libya. The goal of the first phase is studying, planning, and preparation of ITT. At this phase, both transferor and transferee are responsible for delivering the phase's activities and actions with responsibility rate of $70 \%$ and $30 \%$, respectively. They will study and act on: 1. Identify technology, 2. Evaluate technology, 3. Secure technology, 4. Identify barriers, 5 .

Design $\mathrm{T}$ tr model. The goal of the second phase is the preparation of receiving technology, implementation, and management. At this phase, most initiative is from transferee end with responsibility rate of $70 \%$ while transferor will act with responsibility rate of $30 \%$. They should continue to act on: 1. Technology awareness, 2. Technology training, 3. Technology implementation, 4. Technology Sustainability, 5. Technology management. The ITT activities and actions assessment link all the framework elements in order to perform a critical evaluation of the practicability of the process up to each stage. Based on the evaluation process that is performed by the ITT project team at each stage, the project could be authorized to move forward to the next stage or could be put on hold for reviewing, revising, or renegotiation. The ITT project team includes work groups from transferor and transferee, third-party consultant, and process coordinators. All parties of the project team should be involved in the project activities to ensure matching the project goal and objectives between transferor and transferee. The continuous information flow between the transferor and transferee leads to achieve the goal of ITT sustainability development.

\section{CONCLUSION}

The gap between developed and developing countries is wide, especially when it comes to high tech and the use of advanced technology in everyday life. Many developing countries are trying to catch up. One viable way that developing countries could use to bridge the technology gap is technology transfer. However, technology transfer across international borders has unique challenges related to the

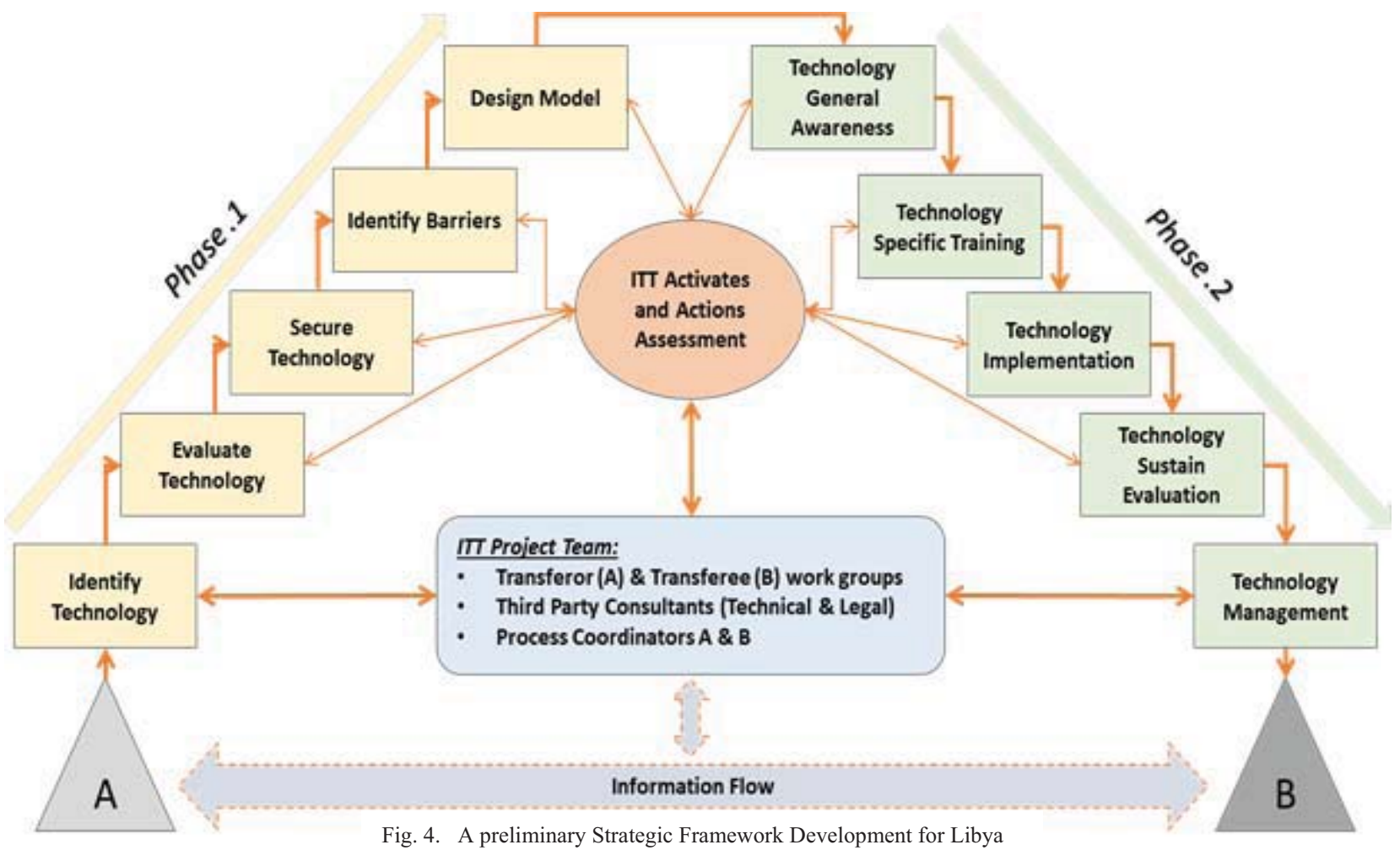


process itself and the particular situation in the recipient country. In this paper, the authors tried to address this issue with a focus on the case of Libya. The authors' approach includes investigating literature review about international technology transfer (ITT), and the current situation in the country of Libya, a developing country that is actively trying to adopt recent advances in technology for the betterment of its people.

The authors studied the technology situation in Libya in terms of technology status, adoption challenges, and the ability to receive technology from abroad. Based on the findings, the authors developed a strategic framework that caters to Libya's need and can be used for sustainable and effective technology transfer in that country. Furthermore, this framework can be used as a guideline or starting point for any developing country as it sheds light on critical issues that must be considered to achieve sustainable technology transfer from developed to developing countries.

\section{LIMITATION AND FUTURE WORK}

This work represents an extensive literature review. Therefore, it can be researched further by conducting interviews with experts related to technology transfer in Libya, as well as by conducting thorough research on previous technology transfer projects in that country.

\section{REFERENCES}

[1] A. Sajid, P. Vinay, and S. Chander, "Technology transfer in pharmaceuticals," Int. Res. J. Pharm., 2012.

[2] C. U. Saraf, "Elements of managing transfer of technology from laboratory to industry: Technology transfer management (TTM)," J. Sci. Ind. Res. (India)., 2014.

[3] A. A. M. Osman-Gani, "International technology transfer for competitive advantage: A conceptual analysis of the role of HRD," Compet. Rev., 1999.

[4] I. Nygaard and U. E. Hansen, "Overcoming Barriers to the Transfer and Diffusion of Climate Technologies. Denmark," 2012.

[5] C. N. Madu, "Transferring technology to developing countries-Critical factors for success," Long Range Plann., 1989.

[6] M. D. Janodia, D. Sreedhar, V. S. Ligade, A. Pise, and N. Udupa, "Facets of technology transfer: A perspective of pharmaceutical industry," J. Intellect. Prop. Rights, 2008.

[7] A. J. Minchener, "Technology transfer issues and challenges for improved energy efficiency and environmental performance in China," Int. J. Energy Res., 2000.

[8] D. Leonard-Barton and D. K. Sinha, "Developer-User Interaction And User Satisfaction In Internal Technology Transfer.," Acad. Manag. J., 1993.

[9] A. Erdilek, "International Technology Transfer in the Middle East and North Africa," Management Decision. 1984.

[10] L. Wei, "International technology transfer and development of technological capabilities: A theoretical framework," Technol. Soc., 1995.

[11] G. J. Udo and F. M. Edoho, "Information technology transfer to African nations: An economic development mandate," J. Technol. Transf., 2000.

[12] A. Hassan and M. YusoffJamaluddin, "Modelling international technology transfer process: Evidence from libyan information and communication industry," ARPN J. Eng. Appl. Sci., 2016.

[13] K. Ramanathan, "The polytrophic components of manufacturing technology," Technol. Forecast. Soc. Change, 1994.

[14] B. Bozeman, "Technology transfer and public policy: A review of research and theory," Res. Policy, 2000.

[15] L. Zhao and A. Reisman, "Toward Meta Research on Technology Transfer," IEEE Trans. Eng. Manag., 1992.
[16] K. Ramanathan, "e-strategies for technological capability development," in Portland International\} \{Conference\} on \{Management of \{Engineering\} and \{Technology\} (\{PICMET\}), \{July\} 29, 2001 \{August\} 2, 2001, 2002.

[17] R. Grosse, "International technology transfer in services," J. Int. Bus. Stud., 1996.

[18] B. Madeuf, "International technology transfers and international technology payments: Definitions, measurement and firms' behaviour," Res. Policy, 1984.

[19] A. Nikoueghbal, "Technology Transfer in Developing Countries Challenges and Strategies : Case Study of Iran's Auto Industry," Iran. Econ. Rev., vol. 10, no. 14, 2005.

[20] K. Ramanathan, "An Overview of Technology Transfer and Technology Transfer Models," Chemistry (Easton)., 2011.

[21] D. J. Jeremy, "Technology Transfer in International Business," Bus. Hist. Rev., 1992.

[22] N. M. Reddy and L. Zhao, "International technology transfer: A review," Res. Policy, vol. 19, no. 4, pp. 285-307, 1990.

[23] C. J. Dahlman, B. Ross-Larson, and L. E. Westphal, "Managing technological development: Lessons from the newly industrializing countries," World Dev., 1987.

[24] A. K. Puthanpura, R. Khalifa, and L. Chan, "Assessing emerging automotive technologies for the future," in 2015 Portland International Conference on Management of Engineering and Technology (PICMET), 2015, pp. 2113-2120.

[25] M. A. Cusumano and D. Elenkov, "Linking international technology transfer with strategy and management: a literature commentary," Res. Policy, 1994.

[26] N. Rosenberg, Uncertainty and Technological Change, Book. 2009.

[27] P. Attewell, "Technology Diffusion and Organizational Learning: The Case of Business Computing," Organ. Sci., 1992.

[28] G. Parayil, "The Green Revolution in India: A Case Study of Technological Change," Technol. Cult., 1992.

[29] M. Matsumoto, "Reconsidering Japanese Industrialization: Marine Turbine Transfer at Mitsubishi, 40(1):74-97," Technol. Cult., 1999.

[30] S. M. Moon, "Takeoff or Self-Sufficiency? Ideologies of Development in Indonesia, 1957-1961, 39(2):187," Technol. Cult., 1998.

[31] T. K. Wie, "The major channels of international technology transfer to Indonesia: An assessment," J. Asia Pacific Econ., 2005.

[32] C. N. Madu and R. Jacob, "Strategic planning in technology transfer: A dialectical approach," Technol. Forecast. Soc. Change, 1989.

[33] Y. Prahalad, C; Doz, "The Multinational Mission: Balancing Local Demands and Global Vision,” J. Int. Bus. Stud., 1987.

[34] Balanced Scorecard Institute, "Balanced Scorecard Basics," Balanced Scorecard Institute, 2015.

[35] R. Phaal, C. Farrukh, and D. Probert, "Technology Roadmapping: linking technology resources to business objectives," Int. J. Technol. Manag., 2001

[36] H. Chen, J. C. Ho, and D. F. Kocaoglu, "A strategic technology planning framework: A case of Taiwan's semiconductor foundry industry," IEEE Trans. Eng. Manag., 2009.

[37] K. I. Jagoda, "A Stage-gate Model for Planning and Implementing International Technology Transfer. Doctoral Thesis. University of Western Sydney, Australia.," 2007.

[38] M. Majidpour, "International technology transfer and the dynamics of complementarity: A new approach," Technol. Forecast. Soc. Change, 2017.

[39] S. N. Bar-Zakay, "Technology transfer model," Technol. Forecast. Soc. Change, 1971.

[40] W. Behrman, N. and Wallender, "Transfers of Manufacturing Technology within Multinational Enterprises. Ballinger Publishing Company, Cambridge, MA," 1976.

[41] C. J. Dahlman and L. E. Westphal, "The Meaning of Technological Mastery in Relation to Transfer of Technology," Ann. Am. Acad. Pol. Soc. Sci., 1981.

[42] A. Schlie, M., Radnor A., and Wad, "Indicators of International Technology Transfer. Center for the Interdisciplinary study of science and Technology, NWU, Evanston," 1987.

[43] N. Chantramonklasri, "The development of Technological and Managerial Capability in the Developing Countries. The Macmillan Press, London," 1990. 
[44] R. Keller, T. and Chinta, "International Technology Transfer: Strategies for Success," vol. Vol. 4, No, pp. 33-43, 1990.

[45] Jagoda and Ramanathan, "Critical success and failure factors in planning and implementing international technology transfer: a case study from Sri Lanka.," Portl. Int. Conf. Manag. Eng. Technol., 2005.

[46] N. Kundu, C. Bhar, and V. Pandurangan, "Development of framework for an integrated model for technology transfer," Indian J. Sci. Technol., vol. 8 , no. 35,2015 .

[47] M. M. Group, "Internent World Status, Usages and Publiation Statistics, https://www.internetworldstats.com/africa.htm\#ly," 2018.

[48] P. Intarakumnerd, P. A. Chairatana, and T. Tangchitpiboon, "National innovation system in less successful developing countries: The case of Thailand," Res. Policy, 2002.

[49] D. Vandewalle, Libya since independence: oil and state-building, Cornell University Press, Book. Cornell University Press, 2018.

[50] J. M. Twati, "The Influence of Societal Culture on the Adoption of Information Systems : The Case of Libya," Commun. IIMA, vol. 8, no. 1, pp. 1-12, 2008.

[51] LIAS, "Libya 2020 Vision, a plan for transformative change by 2020 , Libya Institute of Advanced Studies.," 2018.

[52] P. Libya, "Infrastructure Libya', available at: www.projectlibya.com/infrastructure.php/ (accessed 13 May 2017)," 2007.

[53] B. L. Kedia and R. S. Bhagat, "Cultural Constraints on Transfer of Technology Across Nations: Implications for Research in International and Comparative Management," Acad. Manag. Rev., 1988.
[54] A. S. Mohamed, S. M. Sapuan, M. M. H. Megat Ahmad, A. M. S. Hamouda, and B. T. Hang Tuah Bin Baharudin, "Modeling the technology transfer process in the petroleum industry: Evidence from Libya," Math. Comput. Model., 2012.

[55] A. S. Mohamed, S. M. Sapuan, M. M. H. M. Ahmad, A. M. S. Hamouda, and B. T. H. T. Bin Baharudin, "Modeling technology transfer for petroleum industry in Libya: An overview," Sci. Res. Essay, 2010 .

[56] A. N. . R. M., "A Study on Communications and Information Technology in Libya over the Past Decades, IOSR Journal of Business and Management (IOSR-JBM) e-ISSN: 2278-487X, p-ISSN: 23197668. Volume 20, Issue 3. Ver. VI (March. 2018), PP 07-11,” 2018.

[57] A. Hassan, M. Y. Jamaluddin, and A. Queiri, "Technology transfer model for the Libyan information and communication industry," $J$. Teknol., 2016.

[58] S. J. Edgett, "Idea-to-Launch (Stage - Gate) Model : An Overview," Stage-Gate International, 2015.

[59] N. Tzokas, E. J. Hultink, and S. Hart, "Navigating the new product development process," Ind. Mark. Manag., 2004.

[60] K. Jagoda, B. Maheshwari, and R. Lonseth, "Key issues in managing technology transfer projects: Experiences from a Canadian SME," Manag. Decis., 2010

[61] M. Vieira, W. C. Lucato, R. M. Vanalle, and K. Jagoda, "Effective management of international technology transfer projects: Insights from the Brazilian textile industry," J. Manuf. Technol. Manag., 2014. 